\title{
A distinguished mathematical physicist Boris S. Pavlov
}

\author{
I. Y. Popov ${ }^{1}$, P. A. Kurasov ${ }^{2}$, S. N. Naboko ${ }^{3}$, A. A. Kiselev ${ }^{4}$, A. E. Ryzhkov ${ }^{1}$, A. M. Yafyasov ${ }^{3}$, \\ G. P. Miroshnichenko ${ }^{1}$, Yu. E. Karpeshina ${ }^{5}$, V. I. Kruglov ${ }^{6}$, T. F. Pankratova ${ }^{1}$, A. I. Popov ${ }^{1}$ \\ ${ }^{1}$ ITMO University, Kronverkskiy, 49, St. Petersburg, 197101, Russia \\ ${ }^{2}$ Stockholm University, Stockholm, Sweden \\ ${ }^{3}$ St. Petersburg State University, St. Petersburg, Russia \\ ${ }^{4}$ Rice University, Houston, Texas, USA \\ ${ }^{5}$ University Alabama at Birmingham, USA \\ ${ }^{6}$ Centre for Engineering Quantum Systems, School of Mathematics and Physics, \\ The University of Queensland, Brisbane, QLD 4072, Australia \\ *popov1955@gmail.com
}

PACS 01.60. $+q$

DOI $10.17586 / 2220-8054-2016-7-5-782-788$

Keywords: mathematical physics.

Received: 10 September 2016

Revised: 1 October 2016

Professor Boris Pavlov passed away on 30 January 2016.

Boris Pavlov was born in Kronshtadt, Russia, 27 July 1936. He graduated from Physical faculty of Leningrad State University in 1958 and continued to work at the Department of Mathematical Physics. His PhD thesis (1964, Supervisor - M. S. Birman) was devoted to investigation the spectrum of non-self-adjoint operator $-y^{\prime \prime}+q y$. Ten years later, his $\mathrm{PhD}$ Thesis was followed by a Doctoral dissertation in Mathematical Analysis: "Dilation Theory and Spectral Analysis of Nonselfadjoint Differential Operators". He was a Vice-rector (Research) of Leningrad University [1978-1981 and at the same time [1978-1982], he had a Chair of Mathematical Analysis at the Faculty of Mathematics and Mechanics of Leningrad State University. Later [1982-1995] he worked as a Professor at the department of Higher Mathematics and Mathematical Physics, Physics Faculty. The year 1995 was a branching point for him. He held a Personal Chair in Pure Mathematics at the University of Auckland from 1994 to 2007 , however, he did not break his connections with Russia. From 1995 he was a Chief of Complex Systems Theory Laboratory at Physical Faculty. Since 2009, he was a member of the then newly formed Institute for Advanced Study at Massey University Albany.

B. S. Pavlov was well known for his high level of scholarship in diverse areas of analysis. He became a Fellow of the Royal Society of New Zealand in 2004 and a member of the Russian Academy of Natural Sciences in 2010. B. S. Pavlov leaves behind his wife Irina, a daughter and a son.

The highest scientific achievements of B.S. Pavlov (as he himself felt) are:

- Spectral theory of singular differential non-selfadjoint operators, 1962.

- Riesz-basis property of exponentials on a finite interval, 1979.

- Operator-theory interpretation of critical zeros of the Riemann zeta-function, 1972.

- Symmetric Functional Model for dissipative operators, 1979.

- Zero-range potentials with inner structure and solvable models, 1984.

- Theory of the shift operator on a Riemann surface, jointly with S. Fedorov. 1987.

- Modified analytic perturbation procedure ("Kick-start") for operators with eigenvalues embedded into continuous spectrum, 2005.

- Fitting of zero-range solvable model of a quantum network based on rational approximation of the Dirichleto-Neumann map of the original Hamiltonian, 2007.

- Fitted solvable model of the stressed tectonic plate, in connection with prediction of powerful earthquakes, jointly with L. Petrova, 2008.

- Quasi-relativistic dispersion and high mobility of electrons in Si-B sandwich structures, jointly with N. Bagraev, 2009.

- Theoretical interpretation of the low-threshold field emission from carbon nano-clusters, jointly with Y. Fursey and A. Yafyasov, 2010. 


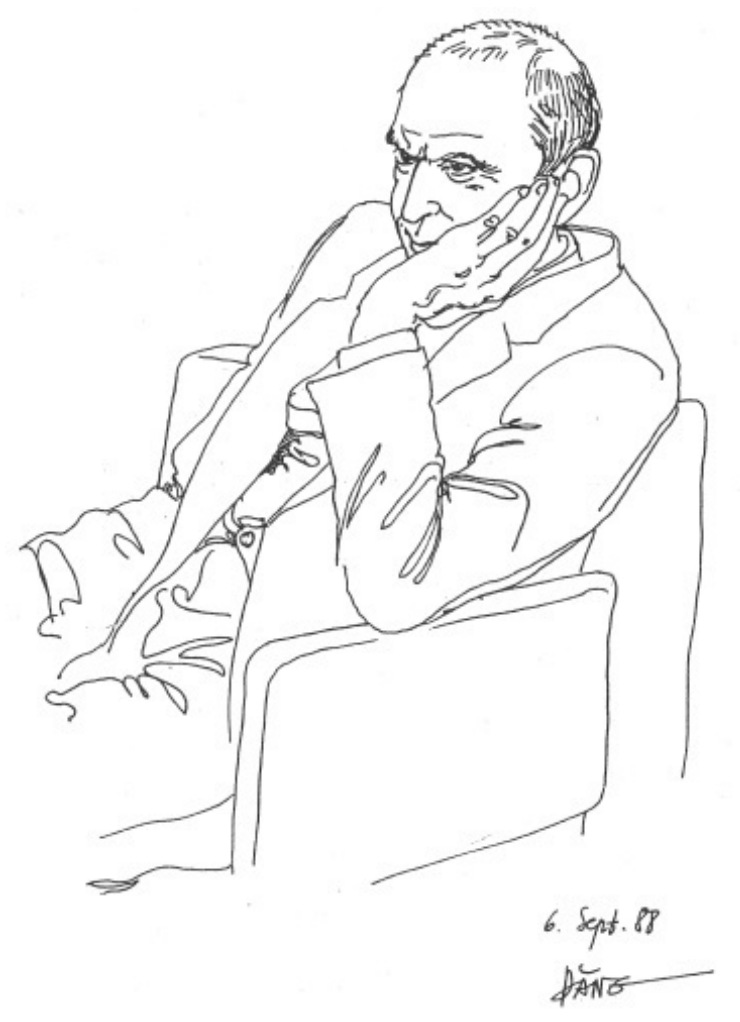

He supervised more than 30 students. Among them were:

1. V. L. Oleinik, Master,PhD student 1965-1971 (Associate Professor, St. Petersburg University)

2. S. V. Petras, Master,PhD student 1965-1970 (Associate Professor, St. Petersburg University of Economics)

3. M. G. Suturin, Master,PhD student 1966-1971 (Associate Professor, St. Petersburg Institute for Airspace devices)

4. S. N. Naboko, Master, PhD student 1969-1976 (Full Professor, St. Petersburg University)

5. S. A. Avdonin, Master,PhD student 1969-1980 (Full Professor, the Univ. of Fairbancs, Alaska)

6. M. A.Shubova, Master,PhD student 1969-1982 (Full Professor, the University of New Hampshire, USA)

7. S. A. Ivanov, Master, PhD student 1972-1978 (Research worker at the Institute of Terrestrial Magnetism RAS, St. Petersburg)

8. I. Yu. Popov, Master, PhD student 1974-1978 (full Professor, Chair of Higher Mathematics, ITMO University, St. Petersburg)

9. Yu. A. Kuperin, Master student 1975-1978 (Doctor of Science, Full Professor, St. Petersburg University)

10. Y. E. Karpeshina, Master,PhD student 1975-1985 (Full Professor, Birmingham University, Alabama, USA)

11. K. A. Makarov, Master, PhD student 1976-1982 (Full professor, Univ. Missouri-Columbia)

12. S.E. Cheremshantsev, Master, PhD student 1976-1982 (Full Professor, Chair of Higher Mathematics, Orlean University, France)

13. A. V. Rybkin, Master, PhD student 1977-1982 (Full Professor, Univ. of Fairbancs, Alaska)

14. A. V. Strepetov, Master, PhD student 1978-1986 (St. Petersburg Institute of Airspace devices, St. Petersburg, Russia)

15. M. D. Faddeev, PhD student 1982-1985. (Associate Professor in St. Petersburg University)

16. P. B. Kurasov, Master, PhD student 1981-1987 (Associate Professor, Doctor of science, now in Lund University, Sweden)

17. A. E. Ryzhkov, Master, PhD student 1974-1980 (Associate Professor, ITMO University, St. Petersburg)

18. V. A. Evstratov, Master, PhD student 1984-1992 (Assistant Professor St. Petersbufg University till 1994. Now in business)

19. A. A. Shushkov, PhD student 1984-1987 (Assistant Professor St. Petersbufg University till 1991, now somewhere in Canada)

20. N. I. Gerasimenko, PhD student 1985-1987 (Associate Professor at the Higher Military School, St. Petersburg) 
21. M. M. Pankratov, Master, PhD student 1987-1991 (Insurance Company, Switzerland.)

22. S. V. Frolov, Master, PhD student 1988-1993 (Doctor of Technology, Full Professor, ITMO University, St.Petersburg)

23. A. A. Pokrovski, Master, PhD student 1990-1995 (Research worker at the Institute for Physics of St. Petersburg University, St. Petersburg, Russia)

24. R. Killip, Master, PhD student, the Univ of Auckland 1994-1996 (Associate Professor, UCLA, LosAngeles, USA)

25. J. Mac-Cormick, Master student, the Univ. of Auckland 1994-1995 (Research worker in Computer Design Laboratory UCLA)

26. A. Kraegeloh, Master thesis, the Univ. of Auckland 1995-1997 (Insurance company, Germany)

27. M. Harmer, Master,PhD student Auckland 1996-2000 (Post Doc., Prague)

28. A. B. Mikhailova, Master student 2000-2001, St-Petersburg Univ. (Research worker at the Institute for Physics of St. Petersburg University)

29. S. Mau, Master student, 1999-2002, the Univ of Auckland (PhD student, New York Univ., USA)

30. S. Marshall, Master student, the Univ of Auckland 2004-2006 (PhD student at Princeton)

31. S. Dillon, Master thesis, the Univ of Auckland, 2005-2007 (PhD at Massey Uni. NZ)

The scientific interests of B.S. Pavlov were very wide, ranging from quantum physics to earthquakes. But were not his only interests. He liked kayak travels and alpine skiing. Everybody knew him as a good painter. In this article, you can see his self-portrait. For his students, if they had a problem, they could visit Boris Sergeevich, as his door was always open and he would help them using all his abilities and talents. He was kind and wonderful person, a teacher in science and in life. We will never forget him.

To show particular remarkable features of B.S.Pavlov, we include here a few memories from his former students.

A. Kiselev. I had the good fortune to study with Boris Sergeevich Pavlov for several years after I transferred from LITMO to SPbGU in 1989. Boris Sergeevich had set my early direction in mathematics, suggesting problems to work on and topics to study. However, he did much more than that; he truly cared about his students, and provided support and advice not only professionally but in other aspects of life. More than anything, though, he influenced me through his personal example of doing mathematics. For him, mathematics was something to live and breathe, something to enjoy with friends and students. Boris Sergeevich treated his classes as performances, including a bit of occasional improvisation, making those instances some of the most inspiring moments I saw. He liked to say that mathematics is an experimental science. This way of thinking about mathematics - that one should build models, experiments, tirelessly explore the entire landscape surrounding the problem of interest - has become part of my mathematical DNA.

Boris Sergeevich was very generous and gentle with me, but he did not hesitate to provide precise feedback when something needed fixing. I remember my first ever presentation of research paper which I read in order to start working on my own problem. Within five minutes of the start Boris Sergeevich yawned and stopped me and explained that he does not need me to faithfully reproduce all the details. I am not at an exam now - what is the idea? This way my boring report quickly turned into a lively discussion. I am afraid that I could not tell the main idea, however Boris Sergeevich did not let us fail and helped me formulate it in the end (I am pretty sure now he figured it out long before I did but made me discover it myself). Every one of such interactions has been priceless for me. The friendly, supportive and wise guidance of Boris Sergeevich came at a key time in my education and truly helped me grow as a mathematician.

P. Kurasov. I would like to mention B.S. Pavlov's precepts for young scientists:

Do other things than other researchers;

Use other ways than other researchers;

Look sharp during your research;

Read, but do not read much, otherwise you will not be read;

Do not disregard negative results;

Do not "cram your results into explanation" before you have checked it carefully.

This article bibliography contains the papers of B. S. Pavlov in Refereed Journals.

\section{References}

[1] Pavlov B.S., Birman M.S. On the complete continuity of certain imbedding operators. Vestnik Leningrad. Univ. Math. Mekh. Astronom., 1961, 16(1), P. 61-74.

[2] Pavlov B.S. On non-selfadjoint operator on half-axis. USSR Acad. Sciences Doklady, 1961, 141(4), P. $807-810$.

[3] Pavlov B.S. On the spectral theory of non-self-adjoint differential operators. USSR Acad. Sciences Doklady, 1962, 146(6), P. 1267-1270. 
[4] Pavlov B.S., Nikolsky N.K. Eigenvector expansions of non-unitary operators, and the characteristic functions. Proceedings LOMI, 1968, 2, P. 150-203.

[5] Pavlov B.S., Nikolsky N.K. Bases from eigenvectors, characteristic function and interpolation problems in Hardy classes. USSR Acad. Sciences Doklady, 1969, 184(3), P. 550-553.

[6] Pavlov B.S., Nikolsky N.K. Bases of eigenvectors of totally non-unitary contractions. USSR Acad. Sciences Doklady, 1969, 184(4), P. 778-781.

[7] Pavlov B.S., Nikolsky N.K. Bases of eigenvectors of completely non-unitary contractions and characteristic function. Izvestia USSR Acad. Sc., 1970, 34, P. 90-133.

[8] Pavlov B.S., Petras S.V. On singular spectrum of a weakly perturbed multiplication operator. Funct. Analysis and it's applications, 1970, 4(2), P. 54-61.

[9] Pavlov B.S. Scattering theory and nonphysical sheet for systems of ordinary differential equations. USSR Acad. Sc. Doklady, 1970, 193(1), P. 36-39.

[10] Pavlov B.S. The completeness of the set of resonance states for a system of differential equations. USSR Acad. Sc. Doklady, 1971, 196(6), P. $1272-1275$

[11] Pavlov B.S., Oleinik V.L. Embedding theorems for weight classes of harmonic and analytic functions. Proceedings LOMI, 1971, 22, P. 94-102.

[12] Pavlov B.S., Suturin M.G. The sharpness of certain embedding theorem. Proceedings LOMI, 1972, 30, P. $170-171$.

[13] Pavlov B.S. Factorization of scattering matrix and serial structure of it's rootes. Izvestia USSR Acad. Sc., Math., 1973, 37, P. $217-246$.

[14] Pavlov B.S., Faddeev L.D. Scattering theory and automorphic functions. Proc.LOMI, 1972, 6(27), P. 161-193 (in Russian); (English Transl.: J. Soviet Math. 1975, 3(4), Consultants bureau, New York-London).

[15] Pavlov B.S. On one-dimensional scattering of plane waves on an arbitrary potential. Teor. i Mat. Fiz., 1973, 16(1), P. 105-119.

[16] Pavlov B.S. The continuous spectrum of resonances on the nonphysical sheet. Soviet Math. Dokl., 1972, 13(5), P. 1301-1304.

[17] Pavlov B.S. To the spectral analysis of dissipative operators. USSR Acad. Sc. Doklady, 1973, 212(2), P. $298-301$.

[18] Pavlov B.S. On expansion by eigenfunctions of absolutely continuous spectrum of a dissipative operator. Vestnik Leningrad University, Math., 1975 1, P. 130-137.

[19] Pavlov B.S. Conditions of separation for the spectral components of a dissipative operator Math. USSR Izvestija, $1975,9(1)$, P. 113-137.

[20] Pavlov B.S. Self-adjoint dilation of dissipative Schrödinger operator and expansion by it's eigenfunctions. Func. Anal. $i$ ego Prilogenia, 1975, 9(2), P. 87-88.

[21] Pavlov B.S. Calculation of loses in scattering problems. Mat. Sbornik, 1975, 97(139), P. 77-93

[22] Pavlov B.S., Smirnov N.V. Resonance scattering by one-dimensional crystall and thin film. Vestnik Leningrad University, (Phys.-Chem.), 1977, 13(3), P. XX.

[23] Pavlov B.S., Faddeev M.D. Construction of self-adjoint dilation for the problem with the impedance boundary condition. Proc. LOMI, 1977, 73, P. 217-223.

[24] Pavlov B.S., Ivanov S.A. Carleson resonance series in Regge problem. Izvestia USSR Acad. Sc., Math., 1978, 1, P. 26-55.

[25] Pavlov B.S., Faddeev L.D. Zero sets of operator functions with the positive imaginary part. Proc. LOMI, 1978, 81, P. 85-88.

[26] Pavlov B.S., Vasynin V.I., Nikolski N.K. Spectral expansions and Carleson condition. Proc. LOMI, $1978,81$.

[27] Pavlov B.S., Beloserskij G.N. Method of estimations of the relaxation frequences of magnetisation vector for superparamagnetic particles. Vestnik Leningrad University, 1978, 22, P. 12-19.

[28] Pavlov B.S., Adamjan V.M. Trace formula for dissipative operator. Vestnik Leningrad University, math., 1979, 2. P. 5-9.

[29] Pavlov B.S. Partial Scattering matrix, it's factorization and analyticity. USSR Acad. Sc. Doklady, 1979, 244(2), P. 291-295.

[30] Pavlov B.S. Basic property of a system of exponentials and the condition of Muckenhoupt. Soviet Math. Dokl., 1979, 21(1), P. 37-40.

[31] Pavlov B.S., Beloserskij G.N. Motion of the magnetisation vector of superparamagnetic particles in stationary case. Journal of Magnetism and magnetic materials, 1979, 12, P. 34-42.

[32] Pavlov B.S., Ivanov S.A. Vector systems and zeros of entire matrix functions. Vestnik Leningrad University, Math., 1980,2 , P. 25-31.

[33] Pavlov B.S., Beloserskij G.N., Semenov V.G., Korenev N.K. The time development of the magnetic moment of superparamagnetic particles and discrete orientation model, II. Journal of Magnetism and magnetic materials, 1980, 20, P. 1-10.

[34] Pavlov B.S., Beloserskij G.N., Makarov K.A. Discrete orientation model in the theory of superparamagnetism. Vestnik Leningrad University, Phys.-Chem., 1982, 4, P. 12-18.

[35] Pavlov B.S., Faddeev M.D. Spectral analysis of unitary perturbations of contractions. Proc. LOMI, 1982, 115, P. 215-227 (In Russian)(English translation: J. of Sov.Math., 1985, 28, P. 768-776).

[36] Pavlov B.S., Faddeev M.D. Scattering on a hollow resonator with the small opening. Proc. LOMI, 1983, 126, P. 159-169 (J. of Sov.Math., 1984, 27, P. 2527-2533).

[37] Pavlov B.S., Faddeev M.D. A model of free electrons and the scattering problem. Teor. $i$ Mat. Fiz., 1983, 55(2), P. 257-268 (English Translation: Theoret. and Math. Phys., 1983, 55(2), P. 485-492).

[38] Pavlov B.S., Popov I.Yu. A model diffraction by infinitely narrow crack and the theory of extensions. (Russian). Vestnik Leningrad. Univ. Mat. Mekh. Astronom. 1983, 19, P. 36-44.

[39] Pavlov B.S., Smirnov N.V. Spectral properties of one-dimensional disperse crystals. (Russian). Proc. LOMI, 1984,133, P. $197-211$.

[40] Pavlov B.S., Popov I.Yu. Scattering by resonators with the small and point holes. (Russian). Vestnik Leningrad. Univ. Math., 1984, 13, P. 116-118.

[41] Pavlov B.S. A model of zero-radius potential with internal structure. Teor.Mat.Fiz., 1984, 59(3), P. 345-354. (English translation: Theoret. and Math. Phys, 1984, 59(3), P. 544-550).

[42] Pavlov B.S., Popov I.Yu. A travelling wave in a ring resonator (Russian). Vestnik Leningrad. Univ. Phys.- Chem., 1985, 1, P. 99-102.

[43] Pavlov B.S., Kuperin Yu.A., Makarov K.A. One-dimensional model of three-particle resonances. Teor. i Mat. Fiz., 1985, 63(1), P. 78-87 (English translation: Theoret. and Math. Phys., 1985, 63(1), P. 376-382).

[44] Pavlov B.S., Karpeshina Yu.E. Interactions of the zero radius for the bi-harmonic and the poly-harmonic equations. Mat. Zametki, 1986, 40(1), P. 49-59. (English translation: Math. Notes, 1987, 40(1-2), P. 528-533). 
[45] Pavlov B.S., Strepetov A.V. Simultaneous completeness in the case of a continuous spectrum. Funktsional. Anal. i Prilozhen., 1986, 20(1), P. 33-36. (English Translation: Functional Anal. Appl., 1986, 20(1), P. 27-30).

[46] Pavlov B.S., Adamjan V.M. Zero-radius potentials and M. G. Krein's formula for generalized resolvents. Proc.LOMI, 1986 , 149, P. 7-23.

[47] Pavlov B.S., Popov I.Yu. Surface waves and extension theory. Vestnik Leningrad. Univ. Math., 1986, 4, P. 105-107 (In Russian).

[48] Pavlov B.S., Kuperin Yu.A., Makarov K.A. Model of resonance scattering of compound particles. Teoret. Mat.Fiz., 1986, 69(1), P. 100-114 (Russian). (English Translation: Theoret. and Math. Phys. 69,1 (1986) P. 1028-1038).

[49] Pavlov B.S. An electron in the homogeneous crystal of point-like atoms with internal structure I. Teor. i Mat. Fiz., 1987, 72(3), P. 403-415.

[50] Pavlov B.S., Kuperin Yu.A., Makarov K.A. Scattering on a dynamical quark bag. Vestnik Leningrad Univ. Phys.- Chem., 1987, 4, P. 60-62. (Russian)

[51] Pavlov B.S. The spectral aspect of superconductivity - the pairing of electrons. Vestnik Leningrad. Univ. Math., 1987, 3, P. 43-49 (In Russian).

[52] Pavlov B.S. An explicitly solvable one-dimensional model of electron-phonon scattering. Vestnik Leningrad. Univ. Fiz. Khim., 1987, 2, P. 60-66.(Russian)

[53] Pavlov B.S. The theory of extensions and explicitly-solvable models. Russian Math. Surveys, 1987, 42(6), P. 127-168.

[54] Pavlov B.S., Kuperin Yu.A., Makarov K.A., Merkuriev S.P., Motovilov A.K. The quantum problem of several particles with internal structure. I. The two-body problem. (Russian). Theoret. i Mat. Fiz., 1988, 75(3), P. 431-444 (English translation: Theoret. and Math. Phys., 1988, 75(3), P. 630-639).

[55] Pavlov B.S., Kuperin Yu.A., Makarov K.A., Merkuriev S.P., Motovilov A.K. The quantum problem of several particles with internal structure. II. The three-body problem. (Russian). Theoret. i Mat. Fiz., 1988, 76(2), P. 242-260. (English translation: Theoret. and Math. Phys., 1988, 76(2), P. 834-847).

[56] Pavlov B.S., Kurasov P.B. An electron in a homogeneous crystal of point-like atoms with internal structure II. Teor. Mat. Fiz., 1988, 74(1), P. 82-93 (In Russian).

[57] Pavlov B.S., Gerasimenko N.I. A scattering problem on noncompact graphs. Teoret. i Mat. Fiz., 1988, 74(3), P. 345-359 (Russian). (English translation: Theoret. and Math. Phys., 1988, 74(3), P. 230-240).

[58] Pavlov B.S., Shushkov A.A. The theory of extensions and null-range potentials with internal structure (Russian). Mat.Sbornik., 1988, 137(179), P. 147-183. (English Translation: Math. USSR-Sb, 1990, 65(1), P. 147-184).

[59] Pavlov B.S., Fedorov S.I. Harmonic analysis on a Riemann surface. (Russian). Dokl. Akad. Nauk SSSR, 1989, 308(2), P. 269-273 (English translation: Soviet Math. Dokl., 1990, 40(2), P. 316-320).

[60] Pavlov B.S. Boundary conditions on thin manifolds and the semiboundedness of the three-body Schroedinger operator with point potential. Math. USSR Sbornik, 1989, 64(1), P. 161-175.

[61] Pavlov B.S., Kuperin Y., Makarov K., Merkuriev S., Motovilov A. Extended Hilbert space approach to few-body problems. J. Math. Phys., 1990, 31(7), P. 1681-1690.

[62] Pavlov B.S., Kuperin Yu.A., Makarov K.A. An extensions theory setting for scattering by breathing bag. J.Math.Phys., 1990, 31(1), P. 199-201.

[63] Pavlov B.S., Fedorov S.I. Shift group and harmonic analysis on a Riemann surface of genus one. Algebra i Analiz, 1989, 1(2), P. 132-168. (English translation: Leningrad Math. J., 1990, 1(2), P. 447-489).

[64] Pavlov B.S., Evstratov V. Electron-phonon scattering, and an explicitly solvable model of a polaron and a bipolaron (Russian). Probl. Mat. Fiz. (Differential equations. Spectral theory. Wave propagation), Leningrad. Univ., 1991, 13 P. $265-304$ (In Russian).

[65] Pavlov B.S., Pankratov M. Electron transport in quasi-one-dimensional random structure. J. Math. Phys., 1992, 33(8), P. 2916-2922.

[66] Pavlov B.S., Kiselev A., Penkina N., Suturin M. A technique of the theory of extensions using interaction symmetry. Teoret. Mat. Fiz., 1992, 91(2), P. 179-191 (In Russian). ( English translation in Theoret. And Math. Phys., 1992, 91(2), P. 453-461).

[67] Pavlov B.S., Popov I.Yu. An acoustic model of zero-width slits and the hydrodynamical stability of a boundary layer. (Russian). Teoret. $i$ Mat. Fiz., 1991, 86(3), P. 391-401. (English Translation: Theoret. and Math. Phys., 1991, 86(3), P. 269-276).

[68] Pavlov B.S., Frolov S.V. A formula for the sum of the effective masses for multidimensional lattice. Teoret. I Mat. Fiz., 1991, 87, P. 456-472 (In Russian). (English Translation: Theoret. and Math. Phys., 1991, 87, P. 657-668).

[69] Pavlov B.S., Kurasov P.B. Nonphysical Sheet and Schroedinger Evolution. Proc. of the International Workshop "Mathematical Aspects of the Scattering Theory and Applications”, 1991, P. 72-81. St. Petersburg University, May 20-24, 1991.

[70] Pavlov B.S., Frolov S.V. Spectral identities for zone spectrum in one-dimensional case. Teor. i Mat. Fiz., 1991, 89(1), P. 3-10 (in Russian). (English Translation: Theoret. and Math. Phys., 1992, 89, P. 1013-1019).

[71] Pavlov B.S. A nonphysical sheet for the Friedrichs model. Proc. POMI, 1992, 200, P. 149-155 (In Russian). (English translation: J. Mat Sci., 1995, 77(3), P. 3232-3235.

[72] Pavlov B.S. Nonphysical sheet for the Friedrichs model. Algebra i Analiz, 1992, 4(2), P. $220-233$ (In Russian). ( English translation: St. Petersburg Math. J., 1993, 4(3), P. 1245-1256).

[73] Pavlov B.S., Strepetov A.V. An explicitly solvable model of electron scattering on the inhomogeneity in a thin conductor. Teor. $i$ Mat. Fiz., 1992, 90(2), P. 226-232 (in Russian). (English translation: Theoret. and Math. Phys., 1992, 90(2), P. 152-156).

[74] Pavlov B.S., Adamjan V. High-Temperature superconductivity as a result of a simple and at bands overlapping. Solid State Physics, 1992, 34(2), P. 626-635 (in Russian).

[75] Pavlov B.S., Pokrovski A. An explicitly solvable model of Mssbauer scattering. Teoret. Mat. Fiz., 1993, 95(3), P. 439-450 (In Russian). (English translation: Theoret. and Math. Phys., 1993, 95(3), P. 700-707).

[76] Pavlov B.S., Galoonov G.V., Oleinik V.L. Estimations for negative spectral bands of three-dimensional periodical Schrödinger operator. J.Math.Phys., 1993, 34(3), P. 936-942.

[77] Pavlov B.S., Kurasov P.B., Elander N. Resonances and irreversibility for Schrödinger evolution. International Journal of Quantum Chemistry, 1993, 46(3), P. 401-414.

[78] Pavlov B.S., Kiselev A.A. Essential spectrum of the Neumann problem for Laplace operator in a model domain of complex structure. Teor. Math. Phys. 1994, 99(1), P. 3-19 (In Russian). (English translation: Theoret. and Math. Phys., 1994, 99(1), P. 383-395).

[79] Pavlov B.S., Makarov K. Quantum scattering on Cantor Bar. Journ. Math. Phys., 1994, 35(4), P. 1522-1531. 
[80] Pavlov B.S. Nonphysical sheet for perturbed Jacobian. Matrices Algebra i Analiz., 1994, 6(3), P. 185-199 (In Russian). (English translation: St. Petersburg Math. J., 1995, 6(3), P. 619-633).

[81] Pavlov B.S., Kuperin Y., Rudin G., Vinitskij S. Spectral geometry: two exactly solvable models. Phys. Letters A, 1994, 194, P. 59-63.

[82] Pavlov B.S., Melnikov Y. Two-body scattering on a graph and application to simple nanoelectronic devices. Journ. Math. Phys., 1995, 36(6), P. 2813-2825.

[83] Pavlov B.S., Geyler V., Popov I. Spectral properties of a charged particle in antidot array: a limiting case of quantum billiard. J. Math. Physics, 1996, 37(10), P. 5171-5194.

[84] Pavlov B.S. Splitting of acoustic resonances in domains connected by a thin channel. New Zealand Journal of Mathematics, 1996, 25, P. 199-216.

[85] Pavlov B.S., Geyler V., Popov I. One-particle spectral problem for superlattice with a constant magnetic field. Atti Seminario Mat. Fis. Univ. Modena, 1998, 46, P. 79-124.

[86] Pavlov B.S. Irreversibility, Lax-Phillips Approach to resonance Scattering and Spectral Analysis of Non-Self-Adjoint Operators in Hilbert Space. International Journal of Theoretical Physics, 1999, 38(1), P. 21-45.

[87] Pavlov B.S., Bridges D., Calude C., Stefanescu D. The constructive implicit function theorem and applications in mechanics. Chaos, Solitons, Fractals, 1999, 10(6), P. 927-934.

[88] Pavlov B.S., Kurasov P. Few-body Krein's Formula. In Operator Theory: Advances and Applications, 118. Operator Theory and related Topics, Vol.2. Birkhauser Verlag, Basel, 2000, P. 225-254.

[89] Pavlov B.S. Scattering problem with physical behavior of the scattering matrix and operator relations (With P. Kurasov) In: Operator Theory: Advances and Applications,113,Complex Analysis, Operators and Related Topics, S.A.Vinogradov - in memoriam, Birkhauser, Basel,(2000) P. 195-204.

[90] Pavlov B.S., Adamjan V. Valuation of bonds and options under oating interest rate. Canadian Math. Society Conf. Proc., 2000,29 , P. 1-14. (Amer. Math. Soc., Providence,RI,2000).

[91] Pavlov B.S., Popov I., Geyler V., Pershenko O. Possible construction of a quantum multiplexer. Europhys letters, 2000, textbf52(2), P. 196-202.

[92] Pavlov B.S., Popov I., Pershenko O. Branching wave-guides as possible element of a quantum computer (in Russian). Izvestija Vuzov, Priborostroenie, 2000, 43(1-2), P. 31-35. (Proceedings of High Education Institutes, Computer Techniques, 2000, 43(1-2), P. 31-35).

[93] Pavlov B.S., Melnikov Y. Scattering on Graphs and one-dimensional approximation of N-dimensional Schrödinger Operator. Journ. Math. Phys., 2001, 42(3), P. 1202-1228.

[94] Pavlov B.S., Harmer M., Mikhailova A. Manipulating the electron current through a splitting. Proceedings of the Centre for Mathematics and its Applications, ANU, Canberra, Australia, 2001, 39, P. 118-131.

[95] Pavlov B.S., Popov I., Frolov S. Quantum switch based on coupled waveguides. The European Physical Journal B, 2001, 21, P. 283-287.

[96] Pavlov B.S., Mikhailova A., Popov I., Rudakova T., Yafyasov A. Scattering on Compact Domain with Few Semi-Infinite Wires Attached: resonance case. Mathematishe Nachrichten, 2002, 235, P. 101-128.

[97] Pavlov B.S., Krageloh A. Unstable Dynamics on a Markov background and stability in average. Operator Theory Adv. Appl.(Birkhauser, Basel), 2001, 127, P. 423-435.

[98] Pavlov B.S., Calude C. Coins, quantum measurements, and Turing's barrier. Quantum Information Processing, 2002 1(2), P. $107-127$.

[99] Pavlov B.S., Pokrovskij A., Strepetov A. Quasi-relativism,the narrow-gap properties, and the forced dynamics of electrons in solids. Theoretical and Mathematical Physics, 2002, 131(1), P. 506-515.

[100] Pavlov B.S., Bos L., Ware A. On semi-spectral method for pricing an option on a mean-reverting asset. Quant. Finance, 2002, 2(5), P. 337-345.

[101] Oleinik V., Pavlov B. Embedded spectrum on a metric graph (an observation). Proc. POMI, 2003, 300, P. $215-220$.

[102] Pavlov B.S. A remark on Spectral meaning of the symmetric Functional Model. Operator Theory: Advances and Applications, Birkhauser Verlag, Basel, 2004, 154, P. 163-177.

[103] Pavlov B.S., Robert K. Resonance optical switch: calculation of resonance eigenvalues. Waves in periodic and random media (South Hadley, MA, 2002), Contemp. Math., 339, Amer. Math. Soc., Providence, RI (2003) P. 141-169.

[104] Pavlov B.S., Oleinik V., Sibirev N. Analysis of the dispersion equation for the Schrödinger operator on periodic metric graphs. Contemporary Mathematics, Waves in periodic and Random Media, AMS, 2004, 14(2), P. 157-183.

[105] Pavlov B.S., Ryzhii V. Quantum dot and anti-dot infrared photo-detectors: iterative methods for solving the Laplace equations in domains with involved geometry. Theor. Math. Phys, 2004, 141(2), P. 163-177 (In Russian). (English translation: Theor. Math. Phys., 2004, 141(2), P. 1369-1481.

[106] Pavlov B.S., Bagraev N., Mikhailova A., Prokhorov L., Yafyasov A. Parameter regime of a resonance quantum switch. Phys. Rev. B, 2005, 71, P. 165308(1-16).

[107] Pavlov B.S., Antoniou I. Jump-start in analytic perturbation procedure for Friedrichs model. J. Phys. A: Math. Gen., 2005, 38, P. 48114823.

[108] Pavlov B.S., Kruglov V. Operator Extension technique for resonance scattering of neutrons by nuclei. Hadronic Journal, 2005, 28, P. 259-268

[109] Pavlov B.S., Kruglov V. Symplectic operator-extension technique and zero-range quantum models. New Zealand mathematical Journal, 2005, 34,(2), P. 125-142.

[110] Pavlov B.S., Fedorov S. Discrete wave scattering on star-graph. J. Phys. A: Math. Gen., 2006, 39, P. $2657-2671$.

[111] Pavlov B.S. A star-graph model via operator extension. Mathematical Proceedings of the Cambridge Philosophical Society, 2007, 142(02), P. 365-384.

[112] Pavlov B.S., Mikhailova A., Prokhorov L. Intermediate Hamiltonian via Glazman splitting and analytic perturbation for meromorphic matrix functions. Mathematische Nachrichten, 280, 12, (2007) P. 1376-1416.

[113] Pavlov B.S., Rudakova T., Ryzhii V., Semenikhin I. Plasma waves in two-dimensional electron channels: propagation and trapped modes. Russian Journal of mathematical Physics, 2008, 14(4), P. 465-487.

[114] Pavlov B.S., Petrova L. Tectonic plate under a localized boundary stress: fitting of a zero-range solvable model. Journal of Physics A, 2008, 41, P. 085206(15). 
[115] Pavlov B., Rudakova T., Ryzhii V., Semenikhin I. Plasma waves in two-dimensional electron channels: propagation and trapped modes. Russian Journal of mathematical Physics, 2008, 14(4), P. 465-487.

[116] Pavlov B. Krein formula with compensated singularities for DN-Mapping and the generalized Kirchhoff Condition at the Neumann Schrödinger Junction. Russian Journal of Mathematical Physics, 2008, 15(9), P. 364-388.

[117] Pavlov B.S., Bruning J., Martin G. Calculation of the Kirchhoff Coefficients for the Helmholtz Resonator. Russian Journal of Mathematical physics, 2009, 16(2), P. 188-207.

[118] Pavlov B.S., Martin G., Yafyasov A. Resonance one-body scattering on a junction. Nanosystems: Physics, Chemistry, Mathematics, 2010, 1 (1), P. 108-147.

[119] Yafyasov A., Bogevolnov V., Pavlov B., Fursey G., Polyakov M., Ibragimov A. Low-threshold field emission from carbon nanoclusters. Ultramicroscopy, 2011, 111(6), P. 409-414.

[120] Bagraev N., Martin G., Pavlov B.S., Yafyasov A. Landau-Zener effect for a quasi-2D periodic sandwich. Nanosystems: Physics, Chemistry, Mathematics, 2011, 2(4), P. 32-50.

[121] Martin G., Pavlov B., Ivlev I., Petrova L. Solvable model of a localized boundary stress on the tectonic plate with dissipative boundary conditions. CoE Lecture Notes, 2011, 32, P. 51-55.

[122] Bagraev N.T., Martin G.J., Pavlov B.S., Yafyasov A.M., Goncharov L.I., Zubkova A.V. The dispersion function of a quasi twodimensional periodic sandwich using Dirichlet-to-Neumann map. Civil-Comp Proceedings, $2012,99$.

[123] Kruglov V., Makarov K.A., Pavlov B., Yafyasov A. Exponential decay in quantum mechanics. Lecture Notes in Computer Science, 2012, 7160, P. 268-288.

[124] Fursei G.N., Polyakov M.A., Kantonistov A.A., Yafyasov A.M., Pavlov B.S., Bozhevolnov V.B. Field and explosive emission from grapheme-like structures. Technical Physics. The Russian Journal of Applied Physics, 2013, 58(6), P. 845-851.

[125] Adamyan V., Pavlov B. Modified analytic perturbation procedure and chain-rule for scattering matrices. Recent Trends in Analysis, 2013, P. $1-16$.

[126] Martin G.J., Adamyan V.M., Pavlov B.S. Local Inverse Scattering Problem as a Tool of Perturbation Analysis for Resonance Systems. Advances in the Mathematical Sciences, 2014. Translations: American Mathematical Society Translations, 2014,233, P. 1-26.

[127] Goncharov L., Yafyasov A., Pavlov B.S., Martin G.J. The dispersion functions for quasi-2D periodic lattices via Dirichlet-to-Neumann map. Journal of Physics: Conference Series, 2014, 490(1), P. 012237.

[128] Fursey G., Konorov P., Pavlov B., Yafyasov A. Dimensional quantization and the resonance concept of the low-threshold field emission. Electronics, 2015, 4(4), P. 1101-1108.

[129] Danieli C., Rayanov K., Pavlov B., Martin G., Flach S. Approximating metal-insulator transitions. International Journal of Modern Physics B, 2015, 29(6), P. 1550036 (13 p).

[130] Flambaum V.V., Pavlov B.S. A possible resonance mechanism of earthquake. J. Seismology, 2016, 20(1), P. 385-392.

[131] Pavlov B., Yafyasov A. Resonance scattering across the superlattice barrier and the dimensional quantization. Nanosystems: physics, chemestry, mathematics, 2016, 7(5), P. 816-834. 